\title{
De minha vida: Poesia e verdade-sobre a literariedade da autobiografia de Goethe
}

\author{
HELMUT GALLE
}

\section{Literatura e autobiografia}

A AUTOBIOGRAFIA de Goethe pertence ao âmago da obra do weimariano e da literatura memorialística. Mesmo quando o cânone da autobiografia deve ser questionado e relativizado, como no novo Handbook of autobiography/autofiction, Poesia e verdade de Goethe não pode faltar (Wagner-Egelhaaf, 2019, p.1282). Junto às Confessiones de Santo Agostinho, as Confessions de Rousseau e The Prelude de Wordsworth, o livro de Goethe se localiza entre os protótipos do gênero e serviu de modelo de centenas de autobiógrafos posteriores. Para a crítica e a teoria da escrita do eu, o livro foi uma referência desde os inícios da germanística, época focada na biografia dos poetas. Até mesmo no pós-estruturalismo, com suas tendências de negar a existência de um gênero autobiográfico (Man, 1984), Goethe continua sendo o exemplo citado por excelência para comprovar a impossibilidade da autobiografia no sentido tradicional (Walter, 2012).

Diante dessa situação, é muito louvável que a antiga tradução brasileira de Leonel Vallandro (Goethe, 1971), esgotada há décadas, tenha sido substituída por uma sólida edição em capa dura e com uma nova tradução, realizada por Mauricio Mendonça Cardozo, que acrescentou também notas explicativas que facilitam a leitura dessa obra que contém centenas de referências a acontecimentos históricos remotos e pessoas hoje em dia desconhecidas.

No entanto, na abertura dessa nova edição da Editora Unesp de De minha vida: Poesia e verdade, lê-se primeiro uma nota preliminar do coordenador da série, Mario Luiz Frungillo, falando da amplitude dos interesses de Goethe, cujo trabalho se estendeu, além da própria poesia, “à reflexão sobre a literatura e as artes e a estudos e pesquisas no campo das ciências da natureza" (Goethe, 2017 , p.5) A nota continua lastimando que só os especialistas, por enquanto, conhecessem "as obras não literárias, de importância fundamental para quem queira conhecer o autor e sua época mais a fundo" (ibidem), formulando como objetivo dessa coleção facilitar o acesso à “obra não literária”. Não cabe dúvida que as partes "não literárias” da vasta produção do weimariano mereçam ser traduzidas e publicadas no Brasil - embora boa parte da sua literatura "poética" propriamente dita ainda seja desconhecida aqui. ${ }^{1}$ Se Poesia e verdade deveria ser considerado "não literário", todavia, merece ser discutido. ${ }^{2}$ 
É verdade que a autobiografia muitas vezes é classificada como um gênero pragmático, escrito para pessoas que procuram, sobretudo, informações apresentadas por uma pessoa de interesse público sobre sua própria vida, buscando revelações mais íntimas ou de esclarecimentos políticos. É claro que a autobiografia de um George W. Bush ou de um Franz Beckenbauer ${ }^{3}$ não necessariamente é tratada como "literatura" no sentido de uma obra com excelente estilo ou composição impressionante. Se esse for o critério para excluir a autobiografia de Goethe da sua obra literária, com certeza é injusto, porque o livro ocupa, sem dúvida, o mesmo patamar estético que os romances de Goethe. Pode ser que os escritos administrativos de Kafka, produzidos durante suas horas de escritório, provoquem menos interesse no público geral do que seus romances inacabados - que ele tampouco achou dignos de serem editados. Mas no caso de Goethe, a autobiografia foi concebida desde o início como "obra", não como instrumento subsidiário em função da poesia propriamente dita, mesmo que o título pudesse sugerir isso: a verdade autobiográfica como complemento da ficção poética. Pode ser ainda que era esse tipo de distinção que levou Mario Frungillo a incluir a autobiografia na seção "não literária" - "non fiction" - como se separam nas livrarias anglófonas romance e autografia em seções diferentes.

No entanto, Poesia e verdade realmente marca uma ruptura na história literária por sair de uma classe de textos sem pretensão literária e constituir a autobiografia como gênero literário. De acordo com Klaus-Detlef Müller (1986, p.1046; 1976, p.27ss), a autobiografia do início do século XVIII contava com três tipos: dois eram formas puramente pragmáticas (Zweck- und Gebrauchsformen), a saber a autobiografia do erudito (Gelehrten-Autobiographie) e a autobiografia religiosa, particularmente na sua versão pietista; e o terceiro tipo era a história de vida aventuresca com relações com o gênero das memórias (mémoires) e o relato de viagens. Na geração anterior a Goethe houve novas tendências, entre elas, a secularização da autobiografia religiosa, manifestando-se sobretudo na obra de Rousseau, e a convergência dos outros tipos experimentados por diversos autores alemães, alguns deles contemporâneos e amigos de Goethe, como Karl Philipp Moritz e Johann Heinrich Jung-Stilling. Mas só em Poesia e verdade essas tendências se articulam de uma maneira inovadora que formula o gênero para o futuro: "Goethe utiliza todos os três modelos preconcebidos e forma a partir deles um novo tipo da representação de si mesmo que determina a ideia da autobiografia enquanto gênero" (Müller 1986, p.1047). ${ }^{4}$

Com Goethe, e desde Goethe, a autobiografia pertence potencialmente ao campo da literatura, particularmente quando é escrita por um autor literário. Ser classificada como literatura implica que os públicos, tanto geral quanto o acadêmico, reconhecem, na obra em questão, qualidades que justificam a leitura além das suas funções informativas ou pragmáticas. Quando se analisa o que compõe a literariedade de um texto, identificam-se muitas vezes dois aspectos complementares: um relacionado à sintaxe (discours) e outro relacionado à semântica (bistoire). Assim, Gérard Genette (1992, p.31) formula que: 
A linguagem humana conhece duas formas básicas da literariedade: a constitutiva e a condicional. A constitutiva define, de acordo com as categorias tradicionais, dois grandes tipos ou entidades globais da prática literária: a ficção e a poesia [...]. Literatura ficcional é marcada essencialmente pelo caráter imaginário dos seus objetos, enquanto que a literatura poética [ de diction] essencialmente impressiona por suas qualidades formais.

Partindo dessa distinção, a literariedade de uma autobiografia se basearia nas suas qualidades poéticas, uma vez que seu objeto, na opinião comum, não é imaginário. Para Genette (1992, p.38ss), "textos que cumprem um dos critérios (ou ambos) podem ser considerados obras, ou seja produções de caráter intencionalmente estético" (grifo do autor). Nesse sentido seria necessário e suficiente mostrar que Poesia e verdade apresenta poeticidade, para classificá-la como obra literária. No que segue, tentamos resumir alguns resultados do campo quase insondável dos estudos sobre Goethe que garantem essa poeticidade. Ao mesmo tempo será mostrado que, nesse caso, a questão da ficcionalidade está caindo cada vez mais no enfoque dos pesquisadores de Goethe, até o ponto de suplantar praticamente a referencialidade dessa autobiografia.

\section{O projeto autobiográfico de Goethe}

A autobiografia foi iniciada quando o autor tinha 60 anos e publicada em quatro partes (1811, 1812, 1814 e, postumamente, em 1833). Quando começou a trabalhar no projeto, em 1809 , as obras que consagraram sua fama entre os alemães e no mundo - do Werther até a primeira parte do Fausto - já haviam sido escritas, seu amigo Schiller e sua mãe haviam falecido, o Sacro Império Alemão e o Ancien Régime eram história e o poeta começava a ver a si mesmo como algo histórico (Birus, 2004, p.10-11). Paralelamente à sua obra tardia (Fausto II, Os anos de peregrinação de Wilhelm Meister, O Divã Ocidental-Oriental) ele planejava um projeto autobiográfico abrangente ao qual pertenciam também A viagem na Itália (1813 e 1817), O cerco de Mainz(1822), A campanba na França (1822) e, finalmente, os Tag- und Jahres-Hefte (Cadernos diários e anuários Goethe, 1830), anotações complementares para todos os anos ao longo da vida. Poesia e verdade foi projetado em cinco partes, mas, na terceira, o trabalho começou a estancar e o quarto volume permaneceu fragmento. O grande interesse dedicado à escrita autobiográfica foi formulado já alguns anos antes por Johann Gottfried Herder, no prefácio a uma coletânea: "Descrições de vida deste tipo são verdadeiros legados do modo de pensar de pessoas memoráveis, espelhos das circunstâncias históricas nos quais viviam, e uma prestação de contas prática, mostrando como eles se aproveitaram delas e de si mesmo, assim como eles falharam em si mesmo e no seu tempo" (Herder, 1883, p.375). Ainda que o gênero existisse desde a Antiguidade sob várias denominações como "Confissões", "Vida de...", "Memórias", ou "Curriculum vitae" (Lebenslauf), foi na segunda metade do século XVIII que "a descrição (grafia) da vida (bios) de um indivíduo por ele mesmo (auto)" (Misch, 1949, p.7) se estabelece como forma 
literária propriamente dita (e com seu novo nome) e, nesse processo, Rousseau e Goethe têm o papel mais importante (Galle, 2011, p.39ss). Poesia e verdade assumiu logo o lugar de modelo do autobiográfico para centenas de autores, não apenas de língua alemã.

De fato, os leitores do século XIX buscaram nesse livro sobretudo informações sobre o homem Goethe, sobre seu desenvolvimento nos primeiros 26 anos, sobre as circunstâncias da evolução do "gênio" e das suas obras. Para o filósofo Wilhelm Dilthey (1998, p.28) , a autobiografia de Goethe era o auge do gênero: "Em Poesia e verdade um homem se comporta, em relação a sua própria existência, de maneira universal-histórica". Goethe, o historiador da sua vida, teria transmitido um retrato objetivo e pleno da sua vida interna e externa, de forma que seus leitores poderiam compreender esse indivíduo como ele mesmo teria se compreendido - um modelo exemplar da hermenêutica.

Investir na relação entre ser humano e sua época histórica era, de fato, uma intenção explícita do autor e com isso queria diferenciar-se das Confissões de Jean-Jacques Rousseau, publicadas em 1782 e 1789. No seu prefácio, o autor cita a suposta carta de um leitor - considerada fictícia pela pesquisa germanística (Jessing, 1997, p.278) - solicitando que o poeta, em ocasião da publicação das obras em treze volumes, confiasse ao público “em uma sequência cronológica [...] de maneira contextualizada, tanto as circunstâncias e os humores que lhes [às obras publicadas] deram origem quanto os exemplos que mais o teriam influenciado, sem deixar de mencionar os princípios teóricos envolvidos" (Goethe, 2017 , p.22). Em princípio disposto a atender essa demanda, o autor reflete sobre os obstáculos para tal empreendimento: a escassez de lembranças, a ausência dos antigos esboços e manuscritos e a necessidade de incluir também suas ocupações científicas e tantas outras atividades, "sozinho ou na companhia de amigos". Sobretudo, porém, ele constata que a função essencial de uma autobiografia iria muito além da reconstrução de uma vida individual pois o sujeito devia ser visto dentro do seu contexto histórico e até como produto desse contexto:

Pois esta parece ser a principal tarefa da biografia: apresentar o homem no contexto das relações de seu tempo, mostrar o quanto ele a elas resiste e o quanto delas se beneficia; de que modo elas impactam em sua condição de artista, poeta, escritor. No entanto, isso exige algo quase impossível de se alcançar, a saber: que o indivíduo conheça a si mesmo e a seu século, mantendo-se sempre o mesmo em todas as circunstâncias, ainda que, querendo ou não, o tempo o acabe arrastando consigo, definindo-o e formando-o; o faça de tal modo que se possa dizer que qualquer um nascido dez anos antes ou depois seria, no que diz respeito a seu próprio desenvolvimento cultural e intelectual e à repercussão de sua vida no mundo, um indivíduo completamente diferente. (Goethe, 2017, p.23-4)

Esse propósito foi realizado consequentemente nos quatro volumes, integrando na narrativa sobre o desenvolvimento do sujeito Goethe a cada vez os acontecimentos da história europeia, não como pano de fundo, mas como 
realidade inter-relacionada. Isso acontece, por exemplo, já no primeiro livro, com o terremoto de Lisboa de 1755, um desastre "de proporções trágicas" pelo qual "[d]e uma hora para outra, uma capital imperial magnífica, grande centro comercial e portuário, é completamente arrasada pela catástrofe mais terrível" (Goethe, 2017, p.47). O narrador estende a descrição do evento e suas consequências tanto para o debate filosófico e teológico quanto para "os ânimos, agitados pela inquietude" (ibidem). Todavia, segundo o narrador, também "o menino, tendo de ouvir reiteradamente aquilo tudo, não se deixaria afetar pouco" (ibidem) e sua fé infantil acaba sendo tocada. De forma semelhante, todos os livros integram os acontecimentos históricos, como a Guerra dos Sete Anos, a coroação do futuro imperador José II, a revolução norte-americana, um panorama histórico da literatura alemã ou o movimento "Tempestade e Ímpeto" protagonizado pelo próprio Goethe, sempre criando uma relação íntima e subjetiva entre a história política e cultural e a história de formação do jovem poeta. É evidente que o autor não conseguiu desdobrar os relatos da macro-história a partir da sua memória ou das suas vivências infantis. Logo no começo do projeto autobiográfico ele mandou buscar, em grande escala, livros, documentos e depoimentos pessoais para construir seu tecido histórico-autobiográfico. "O livro narra", como resume a crítica Jane K. Brown (2019, p.1575), "o desenvolvimento religioso, psicológico, artístico e social do autor, apresentando ao mesmo tempo a sociedade na qual ele cresce".

\section{A metamorfose das plantas e a formação do homem}

Se a interação da autobiografia com a época histórica é a primeira caraterística que destaca essa obra de Goethe em seu tempo, a segunda é um aspecto estrutural da história de vida. Já mencionamos o conceito da "formação", central no pensamento de Goethe, que permeia o romance Os anos de aprendizagem de Wilhelm Meister e que tem suas raízes nas pesquisas naturalistas do weimariano. Para ele, "Bildung" (formação) não significava apenas um processo de aquisição de conhecimentos e competências profissionais, mas o desenvolvimento completo do potencial de um sujeito em interação com seu ambiente familiar, social e histórico, demonstrado de maneira modelar na história do jovem Meister. É consequente que, na narrativa autobiográfica, Goethe pretenda mostrar novamente, agora no exemplo real da sua própria vida, como um indivíduo podia evoluir, ora beneficiado, ora impedido pelas circunstâncias históricas, como ele dá a entender no trecho citado do prefácio. Essa formação do ser humano é pensada em plena analogia aos outros seres da natureza. A estância "Daimon", o primeiro poema do ciclo "Urworte. Orphisch" (Palavras primordiais. Órfico), publicado em 1820 nos cadernos Zur Morphologie (Sobre a morfologia), pode ilustrar esse pensamento (Goethe, 1957, p.229):

$\triangle$ AIMQN, Demónio

Como no dia que te fez nascer

O Sol se ergueu para o saudarem os planetas, 
Logo tu começaste e continuaste a crescer

Conforme leis perfeitas e completas.

A ti não fugirás, assim terás de ser,

Assim disseram já Sibilas e Profetas;

Não há Tempo ou Poder capaz de destruir

Forma cunhada que, a viver, quer progredir.

A constelação planetária aqui - como no início da autobiografia - é um símbolo da singularidade do indivíduo, nascido naquele momento diferente de todos os outros momentos da história. Responsável pela especificidade do indivíduo não é, evidentemente, o horóscopo, mas a herança biológica de cada organismo - hoje em dia se falaria de genoma. Numa entrada dos Tag- und Jahres-Hefte, relativa ao ano 1790 e ao Versuch die Metamorphose der Pflanzen zu erklären (Ensaio para explicar a metamorfose das plantas), Goethe (1994, p.20) escreve: "Estava completamente convencido de que um tipo universal, surgindo por metamorfose, passaria por todas as criaturas orgânicas, poderia ser observado bem em todas suas partes em certos graus intermediários e deveria ser reconhecido ainda quando ele se retira modestamente para o oculto no nível mais alto da humanidade". Metamorfose é entendida como a transformação (imaginária) que produz as figuras diferentes, mas aparentadas, de todos os seres. A "planta matriz" (Urpflanze) é a forma básica à qual se pode reconduzir todas as formas complexas das plantas - não no sentido da evolução darwiniana que ainda não estava no horizonte de Goethe (Wenzel, 2012, p.395 ). "Formação", nas plantas e nos animais, é tanto a figura específica de cada espécie e de cada exemplar como também o processo que leva da forma embriônica para o indivíduo maduro; "formação" também diz respeito à relação oculta que vincula todas as espécies entre si. Oito anos antes do ensaio de Goethe, Johann Friedrich Blumenbach (1752-1840), um naturalista alemão, havia descrito a força inerente ao organismo que produz a forma desenvolvida como "nisus formativus" ou "Bildungstrieb" ("impulso de formação"; cf. Schweizer, 2012, p.383; Mücke, 2006, p.27).

Como a planta cresce de acordo com seu plano de desenvolvimento, o homem evolui a partir de uma entidade seminal - em outros momentos chamada de Entelechie ("enteléquia”; cf. Enke, 2012, p.385 ). Num esboço para o prefácio da terceira parte da autobiografia, Goethe explicitava essa relação entre plantas e formação humana:

Antes de eu começar os três volumes, agora publicados, eu pensei em formá-los de acordo com aquelas leis que nos ensina a metamorfose das plantas. No primeiro, a criança deveria bracejar raízes para todos os lados e desenvolver apenas poucos cotilédones [uma ou duas folhas iniciais da planta]. No segundo o moço deveria bracejar galhos gradualmente mais diversificadas com um verde mais vivo e no terceiro volume correr com espigas e panículas para a flor e representar o jovem esperançoso. (Goethe, 1986, p.971) 
Os primeiros dois volumes desenvolvem, livro por livro, o andamento lento e sistemático da formação do jovem poeta, da sua imaginação fantasiosa, da sua eloquência, da capacidade de versificação, da produção dramática e épica; também se apresenta o estado da literatura alemã que ele encontra na juventude e como ele começa a inscrever-se nessa literatura, ainda com trabalhos convencionais que são, do ponto de vista do velho Goethe, imaturos. Ainda assim, o jovem consegue já nessas formas insatisfatórias encontrar sua maneira particular de relacionar vida e literatura. Como ele constata no sétimo livro:

Foi assim que comecei a seguir aquele rumo do qual nunca mais conseguiria me desviar ao longo de toda minha vida: transformava em imagem, em poema tudo aquilo que me alegrasse e me atormentasse, ou que me ocupasse de algum modo. E, fazendo isso, resolvia as questões comigo mesmo, ora me obrigando a reformular minha compreensão do mundo, ora fazendo sossegar em mim minhas tantas inquietações. Ninguém tinha maior necessidade de um dom como esse do que eu mesmo, que vivia sendo constantemente arremessado de um extremo ao outro pela força de minha própria natureza. Portanto, todas as coisas que dei a público não são mais que fragmentos de uma grande confissão. E este livrinho, aqui, não passa de uma tentativa ousada de complementá-la. (Goethe, 2017, p.343)

Ou seja: a poesia seria, para Goethe, a forma como "a vida" vivida - esse algo informe e incompreensível - se transforma em figura e linguagem, em algo inteligível ou, pelo menos, apreensível. Ao mesmo tempo que ele descreve esse mecanismo psíquico que está na raiz da sua poesia, ele afirma que a própria autobiografia faz parte desse empreendimento de compreender-se a si mesmo, escrevendo literatura, na medida em que a autobiografia retoma a verbalização da vida em modalidade e abrangência diferentes. Toda essa trajetória em direção a si mesmo como homem é acompanhada pelos estágios infanto-juvenis do amor e da religião que, como o desabrochar do poeta, encaixam-se no modelo do desenvolvimento orgânico da planta.

No entanto, as duas primeiras partes terminam, no décimo livro, com novas experiências humanas e estéticas no círculo de Herder em Estrasburgo e com o encontro com a jovem Friederike Brion, filha do pastor em Sesenheim, na Alsácia. Goethe tem 21 anos de idade, e são os poemas de amor, as chamadas canções de Sesenheim, que surgem nesse relacionamento, ao mesmo tempo apaixonado e inocente, e que inscreverão o poeta pela primeira vez na história literária. Como a relação amorosa termina com a culpa vivenciada pelo protagonista ao abandonar a moça apaixonada, o episódio também marca uma ruptura na evolução harmoniosa do sujeito e um distúrbio formal na narrativa da vida.

\section{Dissonâncias entre projeto autobiográfico e vida}

É notável que o episódio de Sesenheim se estenda por dois livros $\left(10^{\circ}\right.$ e $11^{\circ}$ ) e atravesse o limite que separa a segunda da terceira parte, ou seja, a metade da obra. Jessing (1997, p.303) enfatizou que isso configura "o centro 
compositivo de Poesia e verdade". Nos primeiros dez livros, a representação das prematuras produções poéticas do jovem era, em si, mais poética e idílica; os livros que se seguem tratam dos trabalhos literários que formam aquilo que é "a obra" de Goethe conhecida pelos leitores e publicada na edição em 13 volumes de Cotta; nessa parte, as obras são encaradas de maneira mais séria, crítica e prosaica. Ao mesmo tempo, segundo Jessing (1997, p.303), a "fuga compositiva" entre o $10^{\circ}$ e o $11^{\circ}$ livro "constitui uma ruptura na concepção que é anunciada no prefácio não publicado da terceira parte: A estruturação poética do texto autobiográfico de acordo com a metamorfose deixaria o lugar ao conceito do demoníaco, devido à pressão dos fatos que já não podem ser ordenados de forma razoável". Com efeito, esse prefácio "suprimido" e já citado, continua constatando o poder destrutivo do destino que pode afetar plantas e seres humanos igualmente:

Os amigos da jardinagem, porém, sabem bem que uma planta não floresce em todo solo, e, no mesmo solo, não em todo verão e que o esforço aplicado nem sempre é remunerado à larga; e assim, essa representação teria tido uma forma mais fresca e serena, se tivesse sido empreendida alguns anos mais cedo ou a um tempo mais favorável. Mas agora está encerrada na sua limitação, como acontece com tudo que assume forma, ela está circunscrita por seu estado individual, do qual nada pode ser tirado ou acrescentado e eu desejo que esta obra, um aborto [Ausgeburt] mais da necessidade do que da escolha, deleite razoavelmente meus leitores e lhes seja útil. Expresso este desejo com mais ênfase, uma vez que me despedirei deles por certo tempo: pois na próxima época, à qual eu deveria avançar, as flores caem, não todas as coroas produzem fruto e este mesmo, onde se encontra, é discreto, se enche devagar e a maturidade hesita. E quantos frutos caem já antes da madurez por causa de contingências diversas e o desfrute, que já parecia ao alcance, é frustrado. (Goethe, 1986, p.971-2)

No entanto, não é contrário ao conceito de formação de Goethe que as forças "escuras" cruzem e afetem o desdobramento dos potenciais do sujeito. Que sua vida não será entendida como um fruto que cai "antes da madurez" é óbvio, e que aqueles anos que viram sua entrada no mundo literário eram marcados por mais resistências e frustrações é consequente porque essa entrada se dava com provocações, escândalos e irritações no campo literário. A tradução de Maurício Mendonça Cardozo que segue à Edição de Hamburgo (ed. Erich Trunz, Goethe, 1981) não contém esse prefácio que se encontra nos paralipômenos da versão do Klassiker Verlag (Goethe, 1986). Mas ela traz a epígrafe desse terceiro volume (Goethe, 2017, p.539): "Cuidou-se para que as árvores não cresçam para os céus". O significado desse provérbio, atribuído a Lutero, é equivalente ao conteúdo do prefácio, retomando, inclusive, a metafórica vegetal. Quem "cuidou" é a instância além do humano que rege a ordem do cosmos. As árvores cuja enteléquia tende para o alto, encontram seus limites; isso é necessário e não diminui seu valor e sua grandeza. Da mesma maneira, é 
necessário que um homem que, na infância e juventude, achou condições tão favoráveis - uma família abastada, um estatuto social elencado, uma educação excelente e um momento propício - tenha que enfrentar algumas dificuldades nos anos de amadurecimento.

Entre essas dificuldades está também o problema do amor. O episódio de Sesenheim termina com o abandono da moça amada. Aos poucos, o jovem poeta começara a perceber que ela, tão graciosa no seu ambiente rural costumeiro, destoava quando introduzida nos círculos urbanos e cultos. Quando a despedida de Estrasburgo se aproxima - ele já defendeu sua tese em direito e cumpriu assim o objetivo oficial do estágio na cidade - o jovem se dá conta que paixão inocente resultou em esperanças que não foram planejadas e que ele não quer cumprir. Para a moça e sua família, a relação podia contar como noivado; para o filho de patrícios e poeta promissor o casamento com a filha ingênua de um pastor rural resultaria como mésalliance. Contudo, ele se despediu, sofrendo tanto da separação quanto da sua culpabilidade.

A resposta de Friederike à minha carta de despedida partiu-me o coração. Era a mesma mão, o mesmo pensamento e o mesmo sentimento que se haviam desenvolvido para mim e por mim. E foi só então que senti o quanto a perda a fez sofrer, mas eu não via possibilidade alguma de repará-la, nem mesmo de aliviá-la. Friederike não saía de minha cabeça, sentia sua falta a todo instante e, o que era muito pior, eu não era capaz de me perdoar por minha própria infidelidade. Gretchen havia sido tomada de mim, Annette havia me abandonado, mas nesse caso, pela primeira vez, era eu o culpado. Ferira profundamente o coração mais adorável que havia e, agora, sentindo falta das benesses a que me habituara aquele amor, vivia a dor insuportável dos tempos sombrios do arrependimento. (Goethe, 2017, p.623)

No entanto, ele é consequente na sua atitude e não retoma a relação, e o narrador comenta seu estado de ânimo da seguinte maneira:

[...] deixei-me levar por meu antigo costume e voltei a buscar guarida na poesia. Dei então seguimento ao meu professar poético, para que, dessa forma autopenitente de expiação, eu me tornasse minimamente digno de uma absolvição interior. As duas Marias no Götz von Berlichingen e no Clavigo, assim como a má figura desempenhada por seus amantes, podem bem ser o resultado da compunção de tais considerações. (Goethe, 2017, p.625)

O trecho mostra bem como o poeta lida com a culpa, elemento central nas autobiografias e confissões. Enquanto Santo Agostinho procura redenção dos seus pecados no diálogo com Deus e Rousseau expõe tudo que ele considera vício e delito diante os olhos dos leitores para ser eximido por eles, Goethe é muito mais discreto quando fala de suas falhas e explica - tudo em terminologia religiosa - que a "absolvição" (Absolution) é dada no seu foro interno na base da "forma autopenitente de expiação" (selbstquälerische Büßung) que constitui o "professar poético" (poetische Beichte), ou seja, ele consegue superar o dissenso consigo mesmo causado pela culpa mediante a obra de arte cuja produção exige 
reviver, na ficção, os tormentos da experiência biográfica. É notável, aliás, como o autor intercalou, nessa história do seu amor com Friederike, observações sobre a literatura francesa e sua recepção na Alemanha, motivadas pelas discussões no círculo dos jovens poetas de Tempestade e Ímpeto, reunido em Estrasburgo. No câmbio entre narrativa de acontecimentos íntimos e aspectos objetivos e históricos, se manifesta tanto a intenção de ancorar a biografia na história, quanto o anseio de uma escrita equilibrada que não se entrega exclusivamente ao sentimento.

Voltando, porém, à ruptura na concepção da autobiografia a partir do modelo da formação humana, essa se torna mais evidente na quarta parte. Goethe retomou a continuação do trabalho somente anos depois, e deixou a redação final ao seu íntimo Eckermann. A quinta parte que figurava nos primeiros esboços nem foi considerada. No $20^{\circ}$ e último livro, as forças incompreensíveis que o autor chama de "demoníacas" cruzam mais explicitamente o andamento da sua vida: de novo, ele se separa de uma mulher amada (Lili Schönemann) por motivos da "razão" (Vernunftgrïnde; Goethe, 2017, p.945), cancela no último momento uma viagem para a Itália, corta os laços com sua existência burguesa e a família em Frankfurt e segue o duque de Weimar para a esfera da política e da corte. O autobiógrafo confessa "quão decisivo não é o acaso, no momento em que tal escolha ganha uma direção, no instante em que se define o escolhido?" (Goethe, 2017, p.944). A decisão de voltar para Lili Schönemann, da qual ele já fugira antes por causa de obstáculos aparentemente insuperáveis, é revista quando o duque Carl August o convida para Weimar e esse acaso determinará todo o resto da biografia de Goethe. A digressão dedicada, poucas páginas antes, ao demoníaco explicita como o controle sobre a própria vida não está nas mãos do homem nesses momentos. Na visão de Goethe, esse demoníaco não "era algo divino, pois parecia irracional; não era humano, pois não tinha inteligência; não era diabólico, uma vez que se mostrava benéfico; não era angelical, pois não raro se comprazia da desgraça alheia" (Goethe, 2017, p.941). De toda maneira, constitui "uma força que, se não é de todo contrária à ordem moral do mundo, por certo a atravessa de um lado ao outro, de modo que bem se poderia tomar uma pela trama e outra pela urdidura" (ibidem, p.943). Pessoalmente Goethe procurou se "resguardar dessa essência medonha, procur[ando] buscar refúgio, como de costume, atrás de uma imagem" (ibidem, p.942).

Uma imagem desse tipo pode ser vista na citação do drama Egmont que fecha o livro e ilustra o violento e demoníaco da contingência que cruza os planos de vida:

Criança, Criança! Chega disso! Como que chicoteados por espíritos invisíveis, os cavalos de sol do tempo sempre disparam à frente do carrocim ligeiro de nosso destino e, a nós, não nos resta mais do que, corajosamente, segurar com firmeza as rédeas, guiando as rodas ora à direita, ora à esquerda, desviando de uma pedra aqui, de um precipício acolá. Para onde vai, quem haverá de saber? Nem bem ele se lembra de onde veio. (ibidem, p.955) 
A última frase da citação do Egmont conclui os 20 livros da autobiografia que exercem a função de reconstruir "de onde veio" esse sujeito. Ao mesmo tempo, como observa Müller (1986, p.1290) no comentário da sua edição, o motivo da carruagem do sol se relaciona ao horóscopo do início e, dessa maneira, providencia um certo fechamento estético formal da obra. Mas isso não pode compensar por completo o fim abrupto dessa obra tão extensa. O grand finale não culmina, portanto, no encontro de si mesmo, na realização harmoniosa da enteléquia do poeta, mas na fuga precipitada de uma situação existencial que virou inviável e parte para um destino desconhecido - pelo menos para o protagonista naquele momento. Na interpretação de Jeßing, o autor se sentiu obrigado a abandonar seu projeto porque era impossível integrar a vida que se segue - as décadas de Weimar com seu leque amplo de atividades políticas, científicas e literárias - numa narrativa bem estruturada como os anos da juventude. A imagem poética que o autor encontra para essa situação já não expressa harmonia e realização, mas inquietude, irracionalidade e heteronomia.

O que apoia esse diagnóstico é um certo desequilíbrio formal. A intenção classicista inicial é perceptível ainda nas proporções da estrutura: quatro volumes, cada um com cinco livros e os livros variando - na tradução brasileira - entre 40 e 60 páginas, pelo menos nas três partes iniciais; no quarto volume, porém, o tamanho dos livros diminui e se aproxima a 30 páginas. A longa fase na qual o autor abandonou o trabalho no quarto volume e a entrega do fragmento para a publicação póstuma por Eckermann são entendidas como sintoma do esfacelamento do projeto: avançando na narração da sua vida adulta, o autor não consegue mais integrar as crises e os dados dispersos numa composição que "ordena os fatos de uma forma significativa" (Jeßing, 1997, p.303) como aconteceu nas primeiras partes.

\section{A ficcionalidade da autobiografia}

O fato de o livro ter sido composto de acordo com uma concepção organológica - a formação e o crescimento das plantas - já suscita em muitos críticos a suspeita de a autobiografia ser ficção. Para Brude-Firnau (1985, p.320), a autobiografia "deve ser lida como romance"; Jacobs (1972, p.96), assim como Jeßing $(1997$, p.280, 322) a chama de "romance de formação"; em outros momentos se usa a denominação "romance de desenvolvimento" ("symbolischer Entwicklungsroman"; Jessing, 1997, p.281; "Entwicklungsroman des Lesers"; Brude-Firnau, 1985, p.331). Esses autores enfatizam a proximidade da autobiografia com o gênero do romance de formação, que surge na mesma época e recebe o impulso decisivo do próprio Goethe - não precisa ser repetido aqui que na concepção de Os anos de aprendizagem de Wilhelm Meister o poeta seguiu a mesma ideia de desenvolvimento.

Um outro gênero ficcional considerado na interpretação de Poesia e verdade é o conto de fadas. Gabriele Blod (2003, p.7) atinou com o fato de Goethe 
falar em cartas sobre a autobiografia como seu "Lebensmärchen" (conto de fadas da vida) e com os diversos contos de fadas que foram inseridos na narrativa em momentos cruciais. Um desses é "O Novo Páris, um conto de menino" (Goethe, 2017, p.73; "Der neue Paris. Knabenmärchen"), inserido no segundo livro como exemplo da força imaginativa de Goethe na sua mais tenra idade; o outro é "A nova Melusina", um conto que o autor supostamente teria narrado para Friederike e suas irmãs em Sesenheim, mas que não aparece textualmente na autobiografia; foi publicado em outro lugar e, posteriormente, incluído no romance Wilhelm Meisters Wanderjahre (Os anos de peregrinação de Wilhelm Meister). Para a crítica, tanto a denominação "Lebensmärchen" quanto a inclusão dos contos na representação da vida obedecem à necessidade goethiana de fazer uso da ficção (conto) para dar a verdade da sua história, algo que já refletiria o título Poesia e verdade. Surgindo no mesmo século XVIII, o conto de fadas seria um gênero exemplar para exercer a faculdade da imaginação, o que era necessário para realizar o objetivo autobiográfico: "A cooperação de conto de fadas e autobiografia promete ser produtiva por bons motivos: os dois gêneros se complementam e se correspondem mutuamente" (Blod, 2003, p.50-1). Ao mesmo tempo, Blod frisa que a inserção dos textos ficcionais e sua recepção exemplar por diversos tipos de ouvintes e leitores na diegese pode ser compreendida como indício para a recepção adequada da própria autobiografia. Ou seja: os leitores de Poesia e verdade poderiam observar formas ingênuas da leitura de ficção (voltadas para o conteúdo) e formas adequadas (voltadas para o valor poético) nos protagonistas da história e no processo de aprendizagem do jovem poeta Goethe. Na base dessa aprendizagem, assim a crítica, os leitores reais deveriam assumir a atitude adequada na recepção da própria autobiografia. O livro avança, desse modo, a ser um texto metapoético e autorreferencial.

Para muitos críticos é particularmente o episódio de Sesenheim que comprova a ficcionalidade da autobiografia. Nicholas Boyle, autor da biografia mais atualizada e abrangente sobre o poeta - os primeiros dois volumes da edição inglesa saíram em 1991 e 2000 - observa sobre os trechos em questão: "A descrição inteira daquele primeiro encontro com Friederike, que Goethe oferece em Poesia e verdade, é comprovadamente livre invenção e muitos dos detalhes que se seguem são tão traiçoeiros como se pode esperar dessa autobiografia mais traiçoeira de todas, ainda que nem tão traiçoeira quanto algumas especulações posteriores sobre o caso" (Boyle, 1995, p.126). O editor da edição de Frankfurt (Müller, 1986, p.1179) comenta que existe, no mínimo, uma contradição entre a cronologia comprovada (a chegada de Herder em Estrasburgo, as viagens de Goethe para Sesenheim) e os acontecimentos narrados por Goethe.

O que pode ter motivado as palavras drásticas de Boyle e que faz parte da maioria das argumentações em favor de uma autobiografia ficcionalizada são as interferências entre o romance The vicar of Wakefield (1766), de Oliver Goldsmith, e a narração do encontro com Friederike Brion. De acordo com Poesia e verdade (Goethe, 2017, p.510ss), houve uma leitura coletiva do romance em 
Estrasburgo, que rendeu a Goethe "invectivas" de Herder sobre sua leitura entusiasta e identificadora, demasiadamente voltada para o conteúdo. "Eu sentia coisas como sente um ser humano, como um jovem; para mim, tudo era muito verdadeiro, presente, cheio de vida. Ele, que não tinha olhos senão para formas e conteúdos $[\text { Gehalt }]^{6}$ percebia claramente que eu me via tocado e arrebatado pelo assunto, e era justamente isso que ele não queria tolerar" (Goethe, 2017, p.513). A trama do romance - um pastor rural com suas filhas cortejadas por um aventureiro vagante que depois se revela como homem nobre e de estrato social superior - apresenta traços muito parecidos à constelação da chegada do jovem Goethe em Sesenheim, e o narrador acentua e comenta essas similitudes: "não esperava ser transportado tão rapidamente desse mundo fictício ["aus dieser fingierten Welt"] para um mundo real tão semelhante ["in eine äbnliche wirkliche"]" (Goethe, 2017, p.514). Por um lado, a crítica supõe que o autor teria modelado sua vivência autobiográfica a partir do romance de Goldsmith, criando assim o "idílio de Sesenheim" em vez de relatar os acontecimentos objetivos. Ao mesmo tempo, críticos recentes enfatizam que é a atitude ingênua diante da ficção, descrita pelo autobiógrafo no comportamento de si como protagonista e mais tarde nas filhas do pastor em Sesenheim - que merece atenção, porque ela indica para o leitor a atitude errada diante da autobiografia. O mundo ficcional de Wakefield seria espelhado no mundo não tão "real" de Sesenheim e o tipo de recepção mostrado pelo leitor Herder deveria ser repetido na recepção real do leitor do livro, a saber: como livro de ficção. Nas palavras de Robert Walter (2012, p.242):

Depois da menção e do tratamento desse texto [The vicar of Wakefield] que - como a personagem de Herder em Poesia e verdade reclama com muito direito - não se presta em nada para a identificação [Einfühlung] e vivência empática ingênua, mas, ao contrário, reflete de maneira crítica exatamente esse tipo de comportamento, segue o episódio de Sesenheim, que transfere o protagonista da autobiografia "desse mundo fictício para um mundo real tão semelhante"; consequentemente devemos colocar um ponto de interrogação nítido nesse caráter real. O episódio, portanto, está sob aguda suspeita de ficcionalidade.

Quando se traça o caminho da crítica de Poesia e verdade em termos da sua suposta ficcionalidade, pode-se constatar que, no início, o livro foi considerado um relato verdadeiro da vida do poeta. A partir de 1900 se estabeleceu a dúvida sobre se Goethe teria mesmo sido muito confiável em certos detalhes e os biógrafos do poeta começaram a buscar outras fontes. Paralelamente, surgiu na primeira metade do século XX a ideia de que o livro, em vez de ser visto como fonte de fatos históricos, deveria ser lido como "obra de arte [...] que nos mostra o homem não como visto de fora e no seu comportamento visível, mas o homem interior [...] assim como ele acredita e deseja ter sido" (Gusdorf, 1998, p.143). Nos últimos 50 anos, parece que a crítica quis superar-se cada vez mais com afirmações sobre a não referencialidade da obra e as intenções metapoéticas 
do autor. Se os primeiros leitores tomaram tudo ao pé da letra, nossos contemporâneos veem exclusivamente resultados de uma ficcionalização e atestam ao Weimariano uma completa aderência ao linguistic turn já 200 anos ante litteram (Walter, 2012, p.248). Parece que os críticos querem sobrepujar-se num furor cada vez mais radical, denegando qualquer relação entre o texto e a realidade histórica do autor. Podemos citar novamente Robert Walter (2012, p.248) que resume, de seu ponto de vista, o estado de coisas nas pesquisas:

Até um texto clássico da autobiografia, visto durante longas décadas de teorização como gênero referencial por excelência, desmente, dessa maneira, o fundamento da teoria e se oferece, por conseguinte, como ponto de partida de uma crítica da teoria da autobiografia a partir de uma perspectiva pós-moderna, crítica ao sujeito. Goethe não escreve sobre acontecimentos que ele mesmo vivenciou e que poderiam - graças à sua grandiosa memória, enaltecida tantas vezes - entrar, sem mais nem menos, no texto; seu relato Poesia e verdade realiza um emplotment da subjetividade, ele constrói um Eu poeta com meios narrativos, aderindo a modelos literários e antecessores intertextuais. A imagem do poeta Goethe que achamos na autobiografia é um constructo que não vive de referências a acontecimentos extratextuais, mas, sobretudo, de relações a outros textos.

\section{O significado de "poesia" e "verdade" na concepção de Goethe}

Para alguém que não acompanhou os desdobramentos da teoria pós-estruturalista e da crítica da autobiografia, a afirmação de que Goethe, em suas memórias, "não escreve sobre acontecimentos que ele mesmo vivenciou" pode parecer estranha, para dizer o mínimo. No entanto, essa vertente não está baseada exclusivamente em alucinações ou projeções. Quem se debruça sobre os trechos respectivos, as cartas e conversas de Goethe, ou o prefácio e os trechos respectivos de Poesia e verdade, necessariamente começa a refletir sobre a relação entre fato e ficção nessa obra. Importante é, contudo, que se mantenha em vista como os trechos foram entendidos na época, e pelo próprio Goethe, para não chegar a conclusões equivocadas, provocadas pelo espírito do nosso presente.

No prefácio da autobiografia, respondendo à carta fictícia de um suposto leitor de suas obras, Goethe reflete, como já observado, sobre a dificuldade de "apresentar o homem no contexto das relações com seu tempo", e conclui: "Quanto ao que, de resto, ainda se possa ter a dizer especialmente sobre sua abordagem algo poética, algo histórica [halb poetische, halb historische Behandlung], para tanto ainda há de surgir ocasião ao longo da narrativa" (Goethe, 2017 , p.24). Aqui a questão é o que seria uma “abordagem algo poética, algo histórica", na proporção "meio a meio" ( halb und halb). Os defensores do linguistic turn costumam entender "poético" como "ficcional", presumindo, portanto, que Goethe admite, já no prefácio, que a autobiografia seria, pela metade, “inventada". É difícil confirmar isso diante das mil páginas dessa narrativa cheia de referências a pessoas, datas e lugares históricos, mesmo quando se admite uma certa porção de "ficcionalização" das vivências mais privadas. 


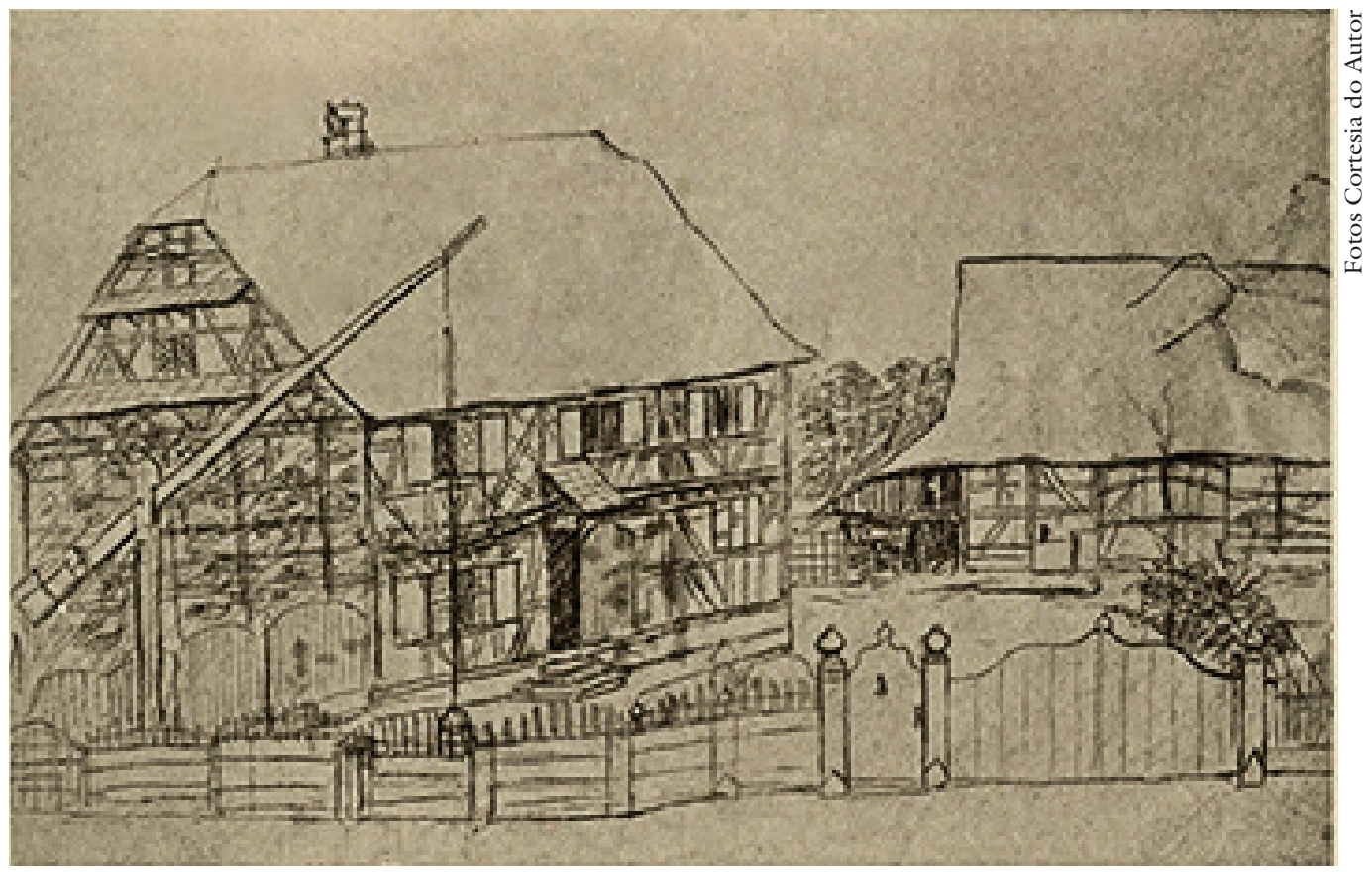

Desenho a sanguinea de Goethe da paróquia de Sesenheim.

Goethe: silhueta (1805).

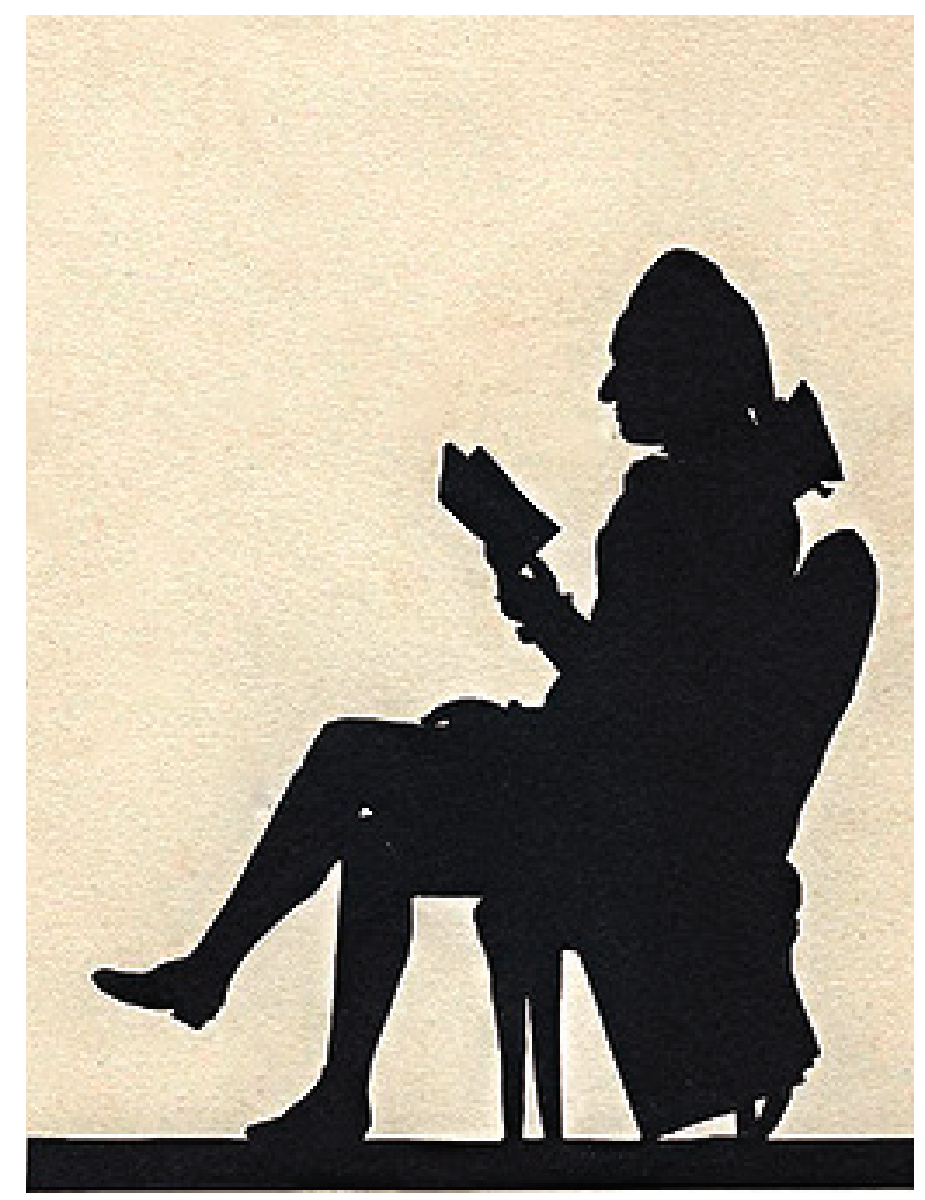


A mesma relação entre ficção e realidade parece ser anunciada já no título Poesia e verdade, uma vez que este não se refere a uma dicotomia entre a obra poética (literária stricto sensu) e o contexto biográfico (verdade), sendo o último revelado no livro autobiográfico como comumente se pensava no século XIX. Para Erich Trunz (1981, p.611), editor da Hamburger Ausgabe, poesia significa o elemento acrescentado aos acontecimentos, pela perspectiva a posteriori do autobiógrafo: "Tudo que na sua autobiografia é interpretação ele chamava de poesia. Os detalhes [...] ele chamava de perdade. Verdade e poesia (que era o título inicialmente) significa, portanto: os fatos e seu contexto".

Em idade avançada, Goethe ainda deu uma explicação abrangente e contraditória na correspondência com o Rei da Baviera:

Quanto ao título - de fato meio paradoxal - das confidências da minha vida, Verdade e poesia [sic], este foi motivado pela experiência de que o público sempre duvida da veracidade de tais tentativas biográficas. Para enfrentar isso, eu admiti uma espécie de fiç̧ão, de certo modo sem necessidade, movido por um espírito de contradição, pois meu objetivo mais sério era representar e expressar, na medida do possível, o essencialmente verdadeiro e fundamental [das eigentlich Grundwahre] que havia reinado em minha vida, de acordo com minha percepção. Mas se isso já não é possível nos anos tardios sem a recordação e, portanto, a imaginação [die Rückerinnerung und also die Einbildungskraft], e como a gente sempre se coloca na situação de exercer, de certa maneira, a faculdade poética [gewissermaßen das dichterische Vermögen auszuüben], então é claro que, em lugar dos detalhes, tal como aconteceram outrora, serão mais os resultados da vida que seriam apresentados e enfatizados, assim como pensamos o passado agora. De fato, a crônica mais comum traz algo do espírito da época na qual foi escrita. (Carta ao Rei Luís I da Baviera, de 12 de janeiro de 1830; Goethe, 1986, p.1056s; grifos nossos)

Num primeiro momento, o autor explica a "poesia" do título como estratégia preventiva contra a incredulidade do público de autobiografias: admitir elementos ficcionais evita ser responsabilizado por trechos duvidosos. Mas, no mesmo instante, ele diz que fez isso "sem necessidade", ou seja: sua veracidade nem merece essa atitude do público. Num terceiro momento, ele afirma que sua veracidade se refere ao "essencialmente verdadeiro e fundamental" e isso não necessariamente deve coincidir com "os detalhes como aconteceram outrora”, mas é figurado por uma memória que, para Goethe, opera sempre com a participação da faculdade imaginativa (Einbildungskraft). Isso é, de fato, uma concepção da recordação que se aproxima bastante às ideias da neurociência do século XXI sobre o funcionamento da memória (Galle, 2011, p.172-218). Por outro lado, não autoriza, em meu modo de ver, a conclusão de Goethe ter apresentado uma ficção no sentido equivalente a um romance ou um conto de fadas.

Importante, nesse contexto, é o conceito de verdade que aparece na carta e que ocupa um lugar central no pensamento de Goethe sobre a realidade e sua 
representação estética. Para Goethe, "a lei que emerge no fenômeno" [ das Gesetz, das in die Erscheinung tritt] é o verdadeiro que, ao mesmo tempo "produz o objetivamente belo" (bringt das objectiv Schöne hervor), assim nas Máximas e reflexões, n.1346 (apud Franz, 1998, p.1116). A contemplação permite intuir, na aparência do fenômeno, aquilo que corresponde à lei, e é a faculdade imaginativa (Einbildungskraft) que produz as imagens que permitem a representação estética da verdade que corresponde à ordem do cosmos, uma verdade superior que está “atrás” dos dados contingentes. Essa concepção idealista - de origem spinozista - subjaz à produção lírica, dramática e épica e também à autobiografia. A diferença é que a autobiografia não representa os tipos universais, mas um caso individual. Exercer a faculdade poética não significa, como bem observou Dieter Borchmeyer (1998, p.488), inventar algo, mas apresentar, no medium da narrativa, aquilo que aconteceu, de acordo com o ponto de vista daquele que fala. Numa conversa com o chanceler von Müller, em 13 de junho de 1825, Goethe especificou essa diferença, respondendo à demanda de Müller que deveria escrever algo sobre a vida na corte de Weimar na época da mãe do duque: "Não seria demasiado difícil, ele respondeu, dever-se-ia tão somente descrever os estados de forma completamente fiel, assim como eles se apresentam ao olho poético na memória; poesia e verdade, sem imiscuir a invenção (Erdichtung)" (Burkhardt, 1870, p.103; grifos no original).

Tudo indica que Goethe teve consciência de que literatura - na época ainda geralmente chamada de "poesia", embora os gêneros prosaicos começassem a integrar esse campo - era constituída pelos dois aspectos distintos que podem ser identificados por poeticidade e ficcionalidade. Como já mencionado no início deste artigo, o primeiro inclui procedimentos basicamente linguísticos, estilísticos e narrativos, e o segundo refere-se à relação das proposições com o mundo. Para Goethe um texto podia ser poético sem dispensar o laço com a realidade histórica. E, já no século XVIII, abundaram romances populares e aventurescos (ou seja: ficções) que Goethe não teria incluído no seu conceito de literatura, porque eles careciam de todo cuidado linguístico e de uma estruturação esmerada. Em Diction e fiction (1991), Gérard Genette analisou com diligência a relação entre os dois aspectos e sua relevância para o conceito europeu de literatura. Afirmações "sérias" sobre a realidade - para usar uma expressão de John Searle (1975) - são feitas em livros de história, artigos jornalísticos e sentenças judiciais, e elas podem ser organizadas em forma narrativa e apresentar traços estilísticos de maior ou menor grau sem que sejam confundidos com "ficção", embora possam conter, evidentemente, erros e mentiras. Mas para que esses sejam tratados como tais, como erros e mentiras, é necessário que os textos sejam lidos como factuais e isso é garantido por convenções da comunicação geralmente descritos como contratos ou pactos de leitura (Lejeune,1975; Eco, 2004, p.103ss), ou instituições (Lamarque; Olsen, 1994, p.37), ou práticas comunicativas (Sprachhandlungspraxis - Zipfel, 2001, p.90). A distinção permite 
optar pelo modo de leitura mais produtivo de um texto - factual ou ficcional -, não a partir da própria textualidade, mas a partir do modo como o texto é sinalizado por autor e editora e sob que rótulo ele circula na sociedade (cf. também Galle, 2018). Para os fins deste artigo, não é preciso entrar em detalhes para mostrar que o emplotment (Hayden White) realizado por um historiador, ou por um autobiógrafo, pode condicionar a interpretação de uma história, mas não suspende sua referencialidade (Zipfel, 2001, p.172ss). Basta citar o que Frank Zipfel afirma sobre a diferença entre poeticidade e ficcionalidade: "Em textos que são literários em virtude da poeticidade, a referência ao mundo é sobreposta (“überlagert”) pela forma, a função poética de Jakobson; em textos que são literários em virtude da ficcionalidade, a referência é suspensa [unterlaufen] pela narração de objetos fictícios" (Zipfel, 2009, p.295). Ou seja: poeticidade pode introduzir ambiguidades e conotações nas afirmações referenciais; a ficcionalidade de uma afirmação exclui a possibilidade da referência imediata. ${ }^{7}$

No caso da autobiografia de Goethe, os paratextos que levam à respectiva sinalização, particularmente o título e o prefácio, incluem certas ambiguidades que já foram descritas. A questão é: devem essas ambiguidades encaminhar a leitura para o pacto ficcional? Ou deve a duplicidade de "poesia e verdade" até ser entendida como oscilação entre dois pactos, atualmente circunscrito sob o conceito da "autoficção"?

No que diz respeito a esta última pergunta, pode-se constatar que até Martina Wagner-Egelhaaf, uma grande defensora desse conceito na abordagem da escrita do eu contemporânea, responde de forma completamente afirmativa. Em sua definição de autoficção, essa é caraterizada por "emprego proposital, consciente e explícito da ficção, na medida em que ela serve para constituir a 'realidade' do eu autobiográfico" (Wagner-Egelhaaf, 2010, p.198). Em relação a Poesia e verdade, segundo essa crítica, a "negação da diferença entre 'realidade' e "ficção" e a resultante "hibridização" só pode ser confirmada pela metade ("Jein") porque o objetivo de Goethe é "tornar compreensível um contexto de vida" (ibidem, p.197). Quando se aplica uma definição de teóricos mais céticos como Marie Darrieussecq (1996, p.377) ou Frank Zipfel (2009, p.305), o novo gênero "demanda ser acreditado $e$ demanda não ser acreditado", uma oscilação contratual que, com certeza, não está nas intenções de Goethe. Mesmo onde ele introduz uma "ficção", como a mencionada carta do leitor no prefácio, a intenção é que o leitor não perceba esse truque. Ele aproxima uma vivência como a de Sesenheim ao romance de Goldsmith, mas não quer dispensar a veracidade do episódio e, ao contrário, manter, na similitude, a diferença quando ele se vê "transportado [...] desse mundo fictício para um mundo real tão semelhante" (Goethe, 2017, p.514).

Que a obra, como um todo, deva ser entendida sob um pacto referencial é evidente quando se considera a intenção de "apresentar o homem no contexto das relações de seu tempo" (Goethe 2017, p.23), sobretudo quando esse 
homem deve ser o próprio autor. O apêndice da edição de Frankfurt inclui um índice onomástico que conta com 58 páginas de nomes que se referem a personalidades históricas e suas obras. Essa referencialidade extensa é uma qualidade central dessa obra de Goethe como da autobiografia em geral. Borchmeyer (1998, p.487) afirma que "verdade no sentido de exatidão histórica era uma preocupação particular de Goethe, como mostram suas pesquisas extensas". Diante disso, certas críticas, feitas com a intenção de invalidar a referencialidade da obra parecem mesquinhas, como a de Blod $(2003$, p.58) ao afirmar que o poeta não inclui muitas datas exatas, ou a de Walter $(2012$, p.253), de que, no episódio de Sesenheim, o autor não usa o nome de família de Friederike e que seus irmãos aparecem - como jogo intertextual explícito - sob os nomes do romance de Goldsmith.

Também é evidente que nenhum crítico começaria a questionar o conteúdo do Werther, do Wilhelm Meister ou do Fausto por divergências com os fatos conhecidos da vida de Goethe. Que isso venha acontecendo há duzentos anos, e continue até na crítica desconstrutivista, significa, em primeiro lugar, que todos esses leitores partem do pacto referencial para mostrar onde Goethe estava confundido ou queria confundir seus leitores - embora os objetivos hoje sejam diferentes: a ideia é questionar principalmente distinções como fato/ficção etc.

É consequente que essa atitude introduz, na análise da autobiografia, a distinção entre autor e narrador, uma operação fundamental para a ficção, onde a voz que profere as proposições sobre o mundo ficcional não coincide com a voz do autor (Zipfel, 2001, p.121). Enquanto o modelo de Lejeune e Genette do pacto autobiográfico ou referencial parte da "identidade" de autor e narrador, a teoria pós-estruturalista postula que o processo de seleção de episódios e sua composição na narrativa (emplotment) já implica uma clivagem entre o sujeito do autor e o narrador do texto: "Nesse processo, o autobiógrafo se transforma em narrador que não é idêntico com a pessoa histórica do autor" (Depkat, 2019 , p.284). Da mesma maneira, a crítica contemporânea de Goethe começou a distinguir o autor Goethe do "narrador de Goethe" (Walter, 2012, p.239), e pergunta: "pode-se confiar num narrador?" (ibidem, p.242). Ao mesmo tempo em que o autor é substituído pela "figura do narrador" (ibidem, p.245), as pessoas às quais o texto se refere aparecem como "personagem de Herder" (ibidem, p.242), ou simplesmente como "Herder", entre aspas. É evidente que uma pessoa física e histórica não pode ser "idêntica" com o sujeito formado por signos linguísticos no texto. Tampouco quando digo "eu" sou idêntico com o som articulado pelos meus órgãos bucais. No entanto, eu e meus ouvintes, enquanto falantes da língua portuguesa, entendem que esse pronome se refere à minha pessoa e que minha intenção é afirmar algo sobre mim mesmo. A consequência dessa ideia desconstrutivista é contraditória e levaria à implosão da comunicação: nem este artigo ou qualquer outra afirmação "séria" poderiam ser relacionados ao seu autor ou ao assunto tratado. 
Podemos supor que Goethe como pessoa, quando estava ditando as frases de Poesia e verdade para seu secretário, queria que suas proposições fossem atribuídas a ele - em vez de uma entidade narradora fictícia - e que ele assumia a responsabilidade por seu conteúdo. De acordo com seu conceito de verdade, é o potencial poético da autobiografia que consegue apresentar aquilo que o poeta considerava o "verdadeiro e fundamental" da sua vida. Sendo o protagonista um indivíduo real, e não um personagem fictício como Wilhelm Meister, as leis que regem essa vida são outras, e mais específicas do que as leis que condicionam a vida da humanidade em geral. Mesmo assim, essa vida particular pode servir de exemplo de como o ser humano se desenvolve em interação com o processo histórico. Assim o poeta observou em 30 de março de 1831, um ano antes da morte, numa conversa com Eckermann: "Pareceu-me - disse Goethe - que meu livro contém alguns símbolos da vida humana. Intitulei-o Verdade e poesia [sic] porque, graças a suas elevadas tendências, ele se coloca acima de uma realidade rasteira" (Eckermann, 2016, p.471). O leitor pode aprender mediante essa apresentação mais do que aprenderia de um relato seco e cronológico, ao mesmo tempo em que a apresentação às vezes "romanesca" proporciona em si uma aprendizagem análoga à que advém de um grande romance, além de ser prazerosa. Coube às interpretações mais recentes ter mostrado que "Poesia e verdade é muito mais do que a narração de uma vida, uma confissão ou memórias de seu tempo. É, entre outras coisas, uma reflexão sobre todas essas formas e, sobretudo, sobre as bases da psicologia que emergiram justamente na virada do século XIX” (Brown, 2019, p.1587).

Para concluir, vale dizer que a crítica recente sobre Poesia e verdade talvez não possa comprovar que essa autobiografia seja inteiramente autorreferencial ou ficcional. O que ela afirma fortemente, porém, é a literariedade da obra, garantida pelo menos por uma elevada poeticidade que não é ofuscada pelas narrativas ficcionais do poeta. Nesse sentido, as palavras do editor que precedem a nova edição, isto é, que o livro seja apresentado na seção "não literária" podem ser vistas como um lapso. Resta afirmar que o leitor brasileiro pode, na tradução de Mauricio Mendonça Cardozo, perceber uma boa parte dessa poeticidade, como já mostram as extensas amostras nas citações deste artigo.

Notas

1 Vale lembrar que boa parte da obra literária não conta com traduções brasileiras a não ser em livros há muito tempo esgotados; os dramas: Götz von Berlichingen, Clavigo, Stella, Egmont, Torquato Tasso, Iphigenie auf Tauris (Ifigênia em Táuride), Die natürliche Tochter (A filha natural); os poemas épicos Reineke Fuchs e Hermann und Dorothea, o romance Wilhelm Meisters Wanderjahre (Os anos de peregrinação de Wilhelm Meister) e o ciclo de novelas Unterhaltungen deutscher Ausgewanderten (Conversações de alemães emigrados), para só mencionar os textos mais importantes. Algumas obras 
menores foram publicadas recentemente por Felipe Vale da Silva (O Grande Cophta, 2017, A criada de Oberkirch, 2015) e o monumental West-östliche Divan (Divã Ocidental-Oriental) está sendo preparado por Daniel Martineschen. Ambos os tradutores também dedicaram suas teses à obra de Goethe. Das Märchen, um pequeno texto meio hermético foi traduzido como $O$ conto da serpente verde e da linda Lilie (2012). E na mesma série da Unesp que apresentou a autobiografia saíram a Viagem à Itália (2017) em tradução de Wilma Patrícia Maas e as Conversações com Goethe nos últimos anos de sua vida por Johann Peter Eckermann (2016), traduzido pelo próprio Mario Frungillo. A plataforma Lattes indica que a tradução de algumas obras foi tema de projetos de Iniciação Científica, os resultados, porém, não se encontram disponíveis no mercado de livros.

2 Vale mencionar que a nota figura em todos os livros da coleção e, pelo que parece, não é um comentário específico sobre os escritos autobiográficos de Goethe ou sobre Poesia e verdade.

3 Muitas vezes essas “autobiografias" nem foram escritas pelos supostos autores, mas produzidas por ghostwriters.

4 Todas as traduções do alemão e do inglês são do autor, com exceção daquelas de Poesia e verdade (Goethe, 2017), das Conversações com Goethe (Eckermann, 2016) e das Poesias de Goethe (1957), marcadas com a respectiva referência.

5 Foi observado que o trecho expressa também a impossibilidade de seguir seu plano de um desenvolvimento harmonioso do sujeito no contexto histórico, uma vez que a queda de Napoleão, observada por Goethe com desagrado e preocupação, abalou sua confiança na marcha da história (cf. Jeßing, 1997, p.321).

6 Em alemão distinguem-se "Inhalt" e "Gehalt"; enquanto o primeiro está relacionado à fábula de uma obra, o segundo se refere mais ao valor intrínseco e pode ser traduzido por "teor".

7 Cf. Strätling (2019) para a questão da referencialidade na autobiografia a partir de uma perspectiva mais pós-estruturalista.

\section{Referências}

BIRUS, H. „Im Gegenwärtigen Vergangnes“. Die Wiederbegegnung des alten mit dem jungen Goethe. GOETHEZEITPORTAL, 19 jan. 2004. Disponível em: <http:// www.goethezeitportal.de/db/wiss/goethe/birus_wiederbegegnung.pdf>. Acesso em: 2 fev. 2019.

BLOD, G. „Lebensmärchen“. Goethes Dichtung und Wahrheit als poetischer und poetologischer Text. Würzburg: Königshausen und Neumann, 2003.

BORCHMEYER, D. Weimarer Klassik. Portrait einer Epoche. Weinheim: Beltz Athenäum, 1998.

BOYLE, N. Goethe. Der Dichter in seiner Zeit. Band 1. 1749-1790. München: Beck, 1995.

BROWN, J. K. Johann Wolfgang Goethe: Aus meinem Leben: Dichtung und Wahrheit (1811-1833) [From My Life: Poetry and Truth]. In: WAGNER-EGELHAAF, M. (Org.) Handbook of autobiography/autofiction, Berlin; Boston: de Gruyter, 2019. p.1573-89. 
BRUDE-FIRNAU, G. Aus meinem Leben. Dichtung und Wahrheit. In: LÜTZELER, P. M.; MCLEOD, J. E. (Org.) Goethes Erzühlwerk. Interpretationen. Stuttgart: Reclam, 1985. p.319-43.

BURKHARDT, C. A. H. Goethes Unterhaltungen mit Kanzler Friedrich von Müller. Stuttgart: Cotta'sche Buchhanldung, 1870.

DARRIEUSSECQ, M. L'autofiction, un genre pas sérieux. Poétique, v.27, p.367-80, 1996.

DEPKAT, V. Facts and Fiction. In: WAGNER-EGELHAAF, M. (Org.) Handbook of autobiography/autofiction. Berlin; Boston: de Gruyter, 2019. p.280-6.

DILTHEY, W. Das Erleben und die Selbstbiographie (1906-1911). In: NIGGL, G. (Org.): Die Autobiographie. Zur Form und Geschichte einer literarischen Gattung. Darmstadt: Wissenschaftliche Buchgesellschaft 199. p. 21-32.

ECKERMANN, J. P. Conversações com Goethe nos últimos anos de sua vida. 1823-1832. Trad. Mario Luiz Frungillo. São Paulo: Editora Unesp, 2016.

ECO, U. Im Wald der Fiktionen. Sechs Streifzüge durch die Literatur. München: dtv, 2004.

ENKE, U. Epigenese. In: WENZEL, M. (Org.): Goethe-Handbuch. Supplemente 2: Naturwissenschaften. Stuttgart, Weimar: Metzler 2012. p. 385-386.

FRANZ, M. Wahres / Gutes / Schönes. In: WITTE, B. et al. (Org.) Goethe Handbuch: Band 4/2 Personen Sachen Begriffe. L-Z, Stuttgart, Weimar: Metzler, 1998. p.1115-17.

GALLE, H. A(s) possibilidade(s) da autobiografia. São Paulo, 2011. Tese (Livre-Docência) - Faculdade de Filosofia, Letras e Ciências Humanas. Universidade de São Paulo. São Paulo, 2011.

. Pequena introdução à teoria da ficcionalidade seguida de uma bibliografia. In: GALlE, H.; PEREIRA, V. S.; PEREZ, J. P. (Org.) Ficcionalidade. Uma prática cultural e seus contextos. São Paulo: Faculdade de Filosofia, Letras e Ciências Humanas, 2018. p.17-43.

GENETTE, G. Fiction et diction. Paris: Seuil, 1991.

Fiktion und Diktion. München: Wilhelm Fink, 1992.

GOETHE, J. W. Poemas. Trad. Paulo Quintela. 2.ed. Coimbra: Acta Universitatis Conimbrigensis, 1957.

. Aus meinem Leben. Dichtung und Wabrheit (Hamburger Ausgabe Bd. 9 und 10). Hamburg: Beck, 1970.

1971.

. Memórias. Poesia e verdade. Trad. Leonel Vallandro. Porto Alegre: Globo,

. Die Metamorphose der Pflanzen (1790). In: TRUNZ, E. (Org.) Werke. Hamburger Ausgabe in 14 Bänden. 9.ed. Hamburg: Beck, 1981. p.64-101.

. Aus meinem Leben. Dichtung und Wabrheit. Org. K.-D. Müller. Frankfurt a.

M.: Deutscher Klassiker Verlag, 1986.

. Aus meinem Leben. Dichtung und Wahrheit (1811-1833). Org. W. Hettche.

Stuttgart: Reclam, 1991. 
GOETHE, J. W. Tag- und Jahreshefte. Org. I. Schmid. Frankfurt a. M.: Deutscher Klassiker Verlag, 1994.

De minha vida. Poesia e verdade. Org. Mário Frungillo. Trad. Maurício Mendonça Cardozo. São Paulo: Editora Unesp, 2017.

GUSDORF, G. Voraussetzungen und Grenzen der Autobiographie (1956). In: NIGGL, G. (Org.) Die Autobiographie. Zur Form und Geschichte einer literarischen Gattung. Darmstadt: Wissenschaftliche Buchgesellschaft, 1998. p.121-47.

HERDER, J. G. Bekenntnisse merkwürdiger Männer von sich selbst. Einleitende Briefe. In: SUPHAN, B. (Org.) Herders Sämmtliche Werke. Berlin: Weidmannsche Buchhandlung, 1883. p.359-76.

JACOBS, J. Wilhelm Meister und seine Brüder. Untersuchungen zum deutschen Bildungsroman. München: Wilhelm Fink, 1972.

JESSING, B. Dichtung und Wahrheit. In: WITTE, B.; SCHMIDT, P. (Org.) Goethe Handbuch Bd. 3 Prosaschriften. Stuttgart: Metzler, 1997. p.278-330.

LAMARQUE, P.; OLSEN, S. H. Truth, Fiction and Literature. A Philosophical Perspective. Oxford: Clarendon Press, 1994.

LEJEUNE, P. Le pacte autobiographique. Paris: Seuil, 1975.

MAN, P. de. Autobiography As De-Facement. In: The Rhetoric of Romanticism. New York: Columbia University Press, 1984. p.67-81.

MISCH, G. Geschichte der Autobiographie. Das Altertum. 3.ed. Frankfurt a. M.: Schulte-Bulmke, 1949.

MÜCKE, D. E. v. Goethe's Metamorphosis: Changing Forms in Nature, the Life Sciences, and Authorship. Representations, v.95, n.1, p.27-53, 2006.

MÜLLER, K.-D. Autobiographie und Roman. Studien zur literarischen Autobiographie der Goethezeit. Tübingen: Niemeyer, 1976.

Kommentar [zu Dichtung und Wabrheit]. Aus meinem Leben. Dichtung und

Wabrheit, Frankfurt a. M.: Deutscher Klassiker Verlag, 1986. p.993-1325.

SCHWEIZER, C. Entelechie. In: WENZEL, M. (Org.): Goethe-Handbuch. Supplemente 2: Naturwissenschaften. Stuttgart, Weimar: Metzler 2012, p. 383.

SEARLE, J. R. The Logical Status of Fictional Discourse. In: New Literary History 6 (1975), Nr. 2, p. 319-332.

STRÄTLING, R. Referentiality. In: WAGNER-EGELHAAF, M. (Org.) Handbook of autobiography/autofiction. Berlin; Boston: de Gruyter, 2019. p.384-9.

TRUNZ, E. Kommentarteil [zu Autobiographische Schriften I]. In: TRUNZ, E. (Org.) Werke. Hamburger Ausgabe in 14 Bänden. 9.ed. Hamburg: Beck, 1981. p.601-865.

WAGNER-EGELHAAF, M. Zum Stand und zu den Perspektiven der Autobiographieforschung in der Literaturwissenschaft. BIOS. Zeitschrift für Biographieforschung und Oral History, v.23, n.2, p.188-200, 2010.

Introduction: Exemplary Autobiographical/ Autofictional Texts, Or, How Not To Set Up A Canon. In: __. (Org.) Handbook of autobiography/autofiction. Berlin; Boston: de Gruyter, 2019. p.1281-4. 
WALTER, R. Aus dieser fingierten Welt in eine ähnliche wirkliche versetzt? Die Theorie der Autobiografie und ein postmoderner Goethe. Goethe Yearbook, v.19, n.1, p.231-60, 2012.

WENZEL, M. Evolution. In: WENZEL, M. (Org.): Goethe-Handbuch. Supplemente 2: Naturwissenschaften. Stuttgart, Weimar: Metzler 2012. p. 393-395.

ZIPFEL, F. Fiktion, Fiktivität, Fiktionalität. Analysen zur Fiktion in der Literatur und zum Fiktionsbegriff in der Literaturwissenschaft. Berlin: Erich Schmidt, 2001.

Autofiktion. Zwischen den Grenzen von Faktualität, Fiktionalität und Literarität. In: WINKO, S.; JANNIDIS, F.; LAUER, G. (Org.) Grenzen der Literatur. Zu Begriff und Phänomen des Literarischen. Berlin; New York: de Gruyter, 2009. p.285314.

RESUMO - O presente artigo discute a relevância da autobiografia de Johann Wolfgang Goethe no cânone da literatura e da escrita do eu, analisando sua composição baseada nas ideias morfológicas do poeta e questionando abordagens mais recentes que aproximam o livro da (auto-)ficção. A discussão é norteada pelo conceito da literariedade e seus aspectos constitutivos, a poeticidade e a ficcionalidade.

PALAVRAS-CHAVE: Autobiografia, Goethe, Metamorfose, Formação, Ficcionalidade, Poeticidade.

ABSTRACT - The article discusses the relevance of Johann Wolfgang Goethe's autobiography to the literary canon and to the genre of writings about one's self, analyzing its composition on the basis of the poet's ideas on morphology and questioning more recent approaches that include the book in the realm of (self)fiction. The discussion is guided by the concept of literariness and its constitutive aspects, poeticism and fictionality.

KEYWORDS: Autobiography, Goethe, Metamorphosis, Education, Fictionality, Poeticism.

Helmut P. E. Galle é professor de literatura alemã no Departamento de Letras Modernas da Faculdade de Filosofia, Letras e Ciências Humanas da Universidade de São Paulo. Doutorado pela Universidade Livre de Berlim, e livre-docente pela USP.

@ - hgalle@usp.br / https://orcid.org/0000-0001-8563-6080

${ }^{\text {I }}$ Faculdade de Filosofia, Letras e Ciências Humanas, Universidade de São Paulo, São Paulo, Brasil.

Recebido em 15.4.2019 e aceito em 16.5.2019. 